\title{
Emergency overflows - consequences of non-compliance with the construction law
}

\author{
Iwona Polarczyk ${ }^{1, *}$ and Michat Fijewski ${ }^{1}$ \\ ${ }^{1}$ Wroclaw University of Science and Technology, Faculty of Environmental Engineering, Wybrzeze \\ Wyspianskiego 27, 50-370 Wroclaw
}

\begin{abstract}
The article is based on a technical opinion that specifies the causes of a construction disaster within an industrial hall that occurred after torrential rain. This article describes the condition before the disaster, provides an analysis of legislation along with a commentary on the analysis of provided materials, in particular - stormwater drainage installation projects from before and after the modernization of the roof - as well as a summary and conclusions.
\end{abstract}

\section{Current condition}

In June 2005, the area on which the industrial hall is located experienced heavy torrential rain which, due to extreme intensity of $561 \mathrm{l} / \mathrm{s} / \mathrm{ha}$ within 5 minutes and $457 \mathrm{l} / \mathrm{s} / \mathrm{ha}$ within 10 minutes, has been classified as centenary rain. In July 2005, in order to protect the hall in the future, the owner decided to implement a Safety Overflow Alternative Project. The project has been agreed with Geberit - the manufacturer of the Pluvia vacuum system. This resulted in an increase in the number of emergency overflows, their surface area, and thus the throughput of the safety system. The water access threshold, according both to the requirements and the project, should be $5 \mathrm{~cm}$ above the lower edge of the inlet. The project was executed, and the investment was concluded.

Renewal of the roof covering was made in 2011. However, as a result, the size and direction of the roof pitch were changed followed by a substantial reduction in the active surface of emergency overflows. Some of the them were completely sealed, while in others their active surface has been limited. Furthermore, the water access threshold to overflows was raised to an average height of approx. $11 \mathrm{~cm}$. This resulted from faulty profiling of roof pitches by placing styrofoam wedges along the attic. At the same time, this procedure led to a shift in the catchment area, which moved into the surface of the roof not subject to direct functioning of the inlets.

In June 2016, heavy rainfall resulted in the destruction of the structural components of the roof covering the high-storage warehouse hall and part of the wall frame construction [Fig. 1 and Fig. 2]. The Institute of Meteorology and Water Management (IMiGW) classified this rain as torrential rain [1]. The decision of the State Construction Inspection identifies sudden downpour and overload due to the weight of residual water as the initial causes of the

\footnotetext{
* Corresponding author: iwona.polarczyk@pwr.edu.pl
} 
disaster. Furthermore, besides structural elements, parts of the electrical system as well as drainage and hydrant systems were destroyed as well [2].

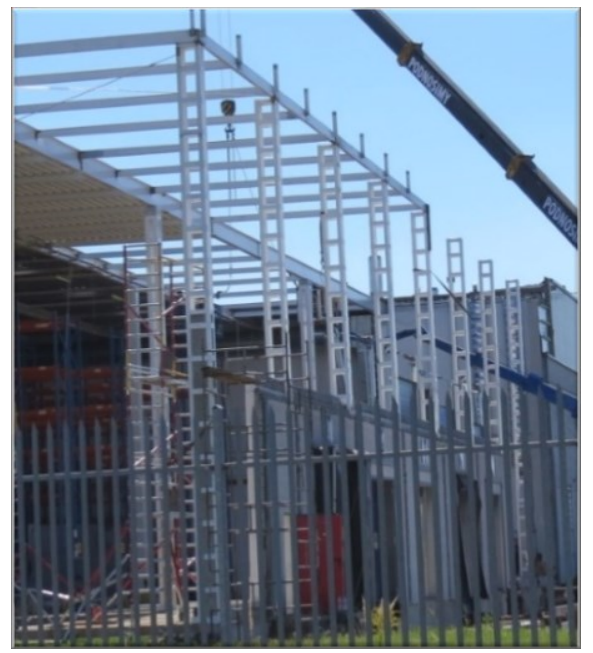

Fig. 1. North-western elevation [4].

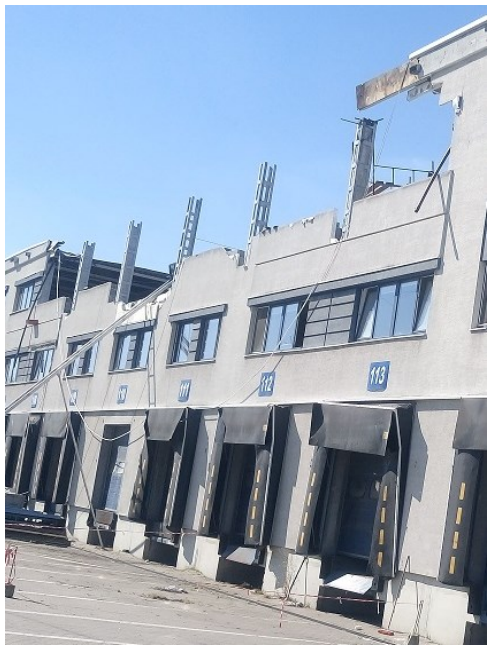

Fig. 2. Front elevation [4].

\section{Legal aspects}

Pursuant to the provisions of Art. 3 of the Construction Law Act [5], whenever in this Act there is a mention of: (...)

8) renovation - it shall mean performing construction works based on the restoration of the original condition of existing building, which are not an ongoing maintenance and allow for the use of construction materials other than those used in the original state.

In the light of Article 62 (1)(3) the buildings should, in time of their use, be subjected by either the owner or the administrator to control (...) periodically to the extent referred to in paragraph 1 , at least two times a year, within the time limits until $31^{\text {st }}$ May and $30^{\text {th }}$ November, in the case of buildings with an area of more than $2.000 \mathrm{~m}^{2}$ and others buildings 
with roof area of more than $1.000 \mathrm{~m}^{2}$; the person making the inspection shall, without delay, in writing, notify the competent authority of the inspection.

According to $\S 315$ of the Regulation of the Minister of Infrastructure on technical conditions to be met by buildings and their locations [6], the building should be designed and constructed in such a way as to precipitation, water in the ground and on the surface, the water used in the building and water vapor in the air in the building do not cause health hazards and safety in use. Whereas roofs and terraces should include pitches for the outflow of rainwater and melting snow to internal or external gutters and downspouts. (§ 319).

General requirements for the safety of vacuum systems are set forth in PN-EN 12056-3 [7], wherein they are referred to as siphonic systems. According to the norm, drainage of flat roofs shall take into account the strength and construction of the roof (point 5.4.1). The installation should be designed so as to prevent water accumulation exceeding the roof's design load. This provision also applies to siphonic systems (point 6.2.2). The siphonic effect shall commence quickly enough to prevent design water depths on the roof being exceeded (point 6.2.3). The subsequent point (point 6.2.13) indicates that the system shall be installed in accordance with the design assumptions, while point 7.4 sets forth that overflows or emergency outlets should be provided on flat roofs with parapets and in non-eaves gutters in order to reduce the risk of overspilling of rainwater into a building or structural overloading.

Due to the fact that provisions relating to the rainwater drainage constitute mere general guidelines, detailed design guidelines are provided by system manufacturers. The project was prepared based on Pluvia system developed by Geberit, which also approved it in terms of safety systems (emergency overflows) and roof inlet systems [3].

\section{Analysis of technical and project documentation, site inspection}

The alternative project for the vacuum system from 2005 as well as the emergency overflow surface forecasted in the project were calculated and selected in accordance with the manufacturer's vacuum rain drainage system. This was confirmed by the company responsible for delivering the system. The project took into account a significant increase in the safety overflow surface due to the occurrence of rain qualified earlier as centennial as well as the possibility of recurrence of extremely heavy rainfall. Based on the abovementioned project, the number of safety overflows with dimensions of $15 \mathrm{~cm}$ (height) and $30 \mathrm{~cm}$ (width) over the warehouse part was increased to 10. Furthermore, 4 overflows with dimensions of $17 \mathrm{~cm}$ (height) and $78 \mathrm{~cm}$ (width) were made with a total area of $9.800 \mathrm{~cm}^{2}$. This allowed to achieve water drainage intensity at $881.7 \mathrm{l} / \mathrm{s}$ *ha. 10 safety overflows with dimensions of $15 \mathrm{~cm}$ (height) and $30 \mathrm{~cm}$ (width), with a total area of $4.500 \mathrm{~cm}^{2}$, were installed over the office part so as to allow for water drainage at $404 \mathrm{l} / \mathrm{s} / \mathrm{ha}$ [3].

However, during the renovation of the roof conducted in 2011, several changes were made, which thus affected the outflow of rain water from the surface of the roof. Additional structures, with a height of approximately $15 \mathrm{~cm}$ in the highest position, were introduced with an aim of lifting the level of the roof at the attic and new pitches towards the center of the roof were profiled, reaching beyond the roof inlet line. These actions resulted in a change to the inclination which led the rainwater outside the rainwater drum into the channel located approx. $3 \mathrm{~m}$ from the attic [Fig. 3], the bottom of which was below the inlet, the foundation of which has not changed. The new channel, due to strength reasons, was located in the worst place - in the arrow of the support beam deflection. In case of heavy rainfall this could have led to a significant delay in the waste outlfow into the drum, the accumulation of water at a considerable distance from the drum, shift in the center of gravity to another position at the roof and different rainwater load distribution than calculated. This, in turn, resulted in 
changes to the supporting structure, thus resulting in the destruction of the roof due to its overload through accumulating rainwater. It should be noted that the height of accumulated water in the trough is a dynamically variable value - the more water there is, the greater the deflection of the roof, and therefore the greater overload through inflowing water. It should also be pointed out that both in the original and alternative project, the inflow and accumulation of water were presumed at the attic, where emergency overflows were located, and not approx. $3 \mathrm{~m}$ from it.

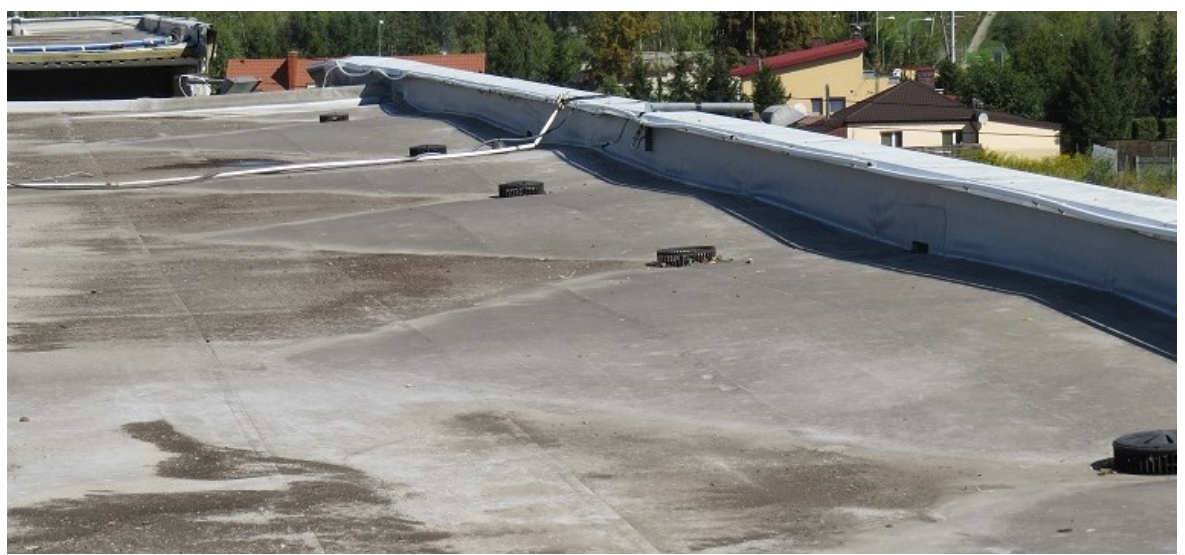

Fig. 3. Roof plan [4].

In addition, as a result of the renovation works the active surface for rainwater drainage from the emergency overflows was reduced:

- directly, by completely covering and sealing some of the openings [Fig. 4 and 5],

- directly, by reducing the area of the overflow openings, by inserting wires with a smaller section - approx. $12 \times 29 \mathrm{~cm}$ - in the existing troughs with dimensions of approx. 15 x $30 \mathrm{~cm}$ [Fig. 6].

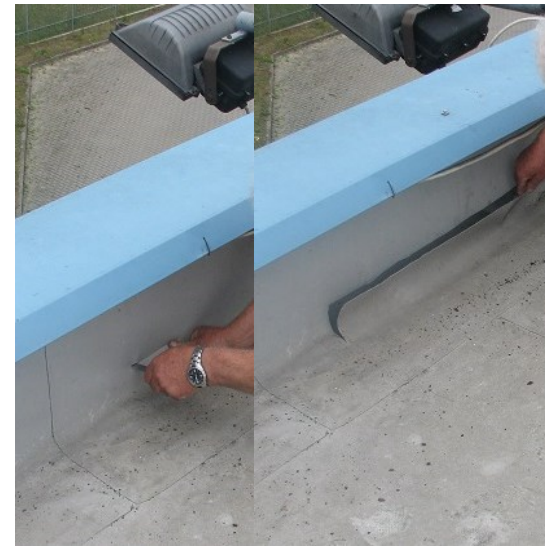

Fig. 4. Closed emergency opening [4]. 


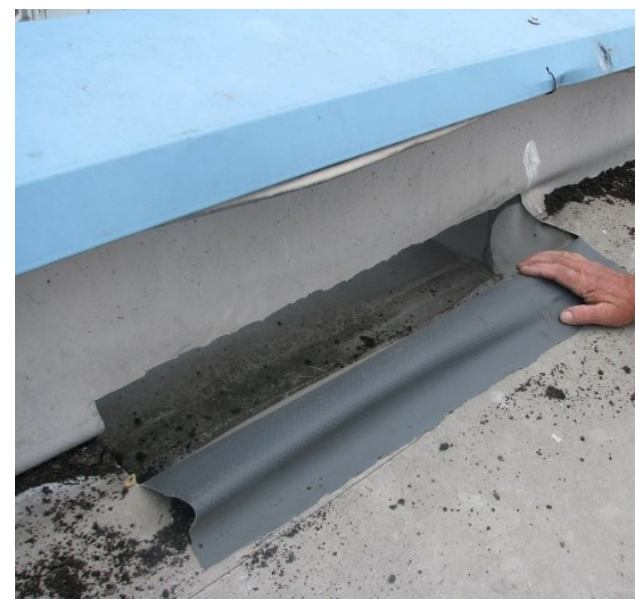

Fig. 5. Closed emergency opening [4].

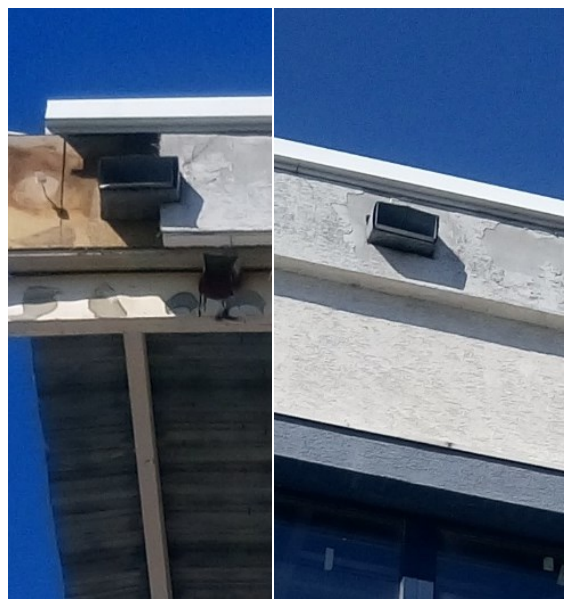

Fig. 6. Reduction of the size of emergency openings [4].

- indirectly, by changing the height of the location of emergency overflows from the lower edge of the overflow to the lowest surface of the roof, which led to the accumulation of more rainwater in this part than originally provided for the project. Water access threshold increased significantly to approx. $12-14 \mathrm{~cm}$. In places where the overflow was located in the recesses between the polystyrene uplift, the bottom edge was raised deliberately [Fig. 7]. As a result, the emergency overflows either failed to work at all or were not functioning properly at an appropriate time. Increasing the level of the roof and performing overflow thresholds resulted in significant accumulation of water in a part of the roof different than designed, thus the emergency openings ceased to fulfill their functions. 


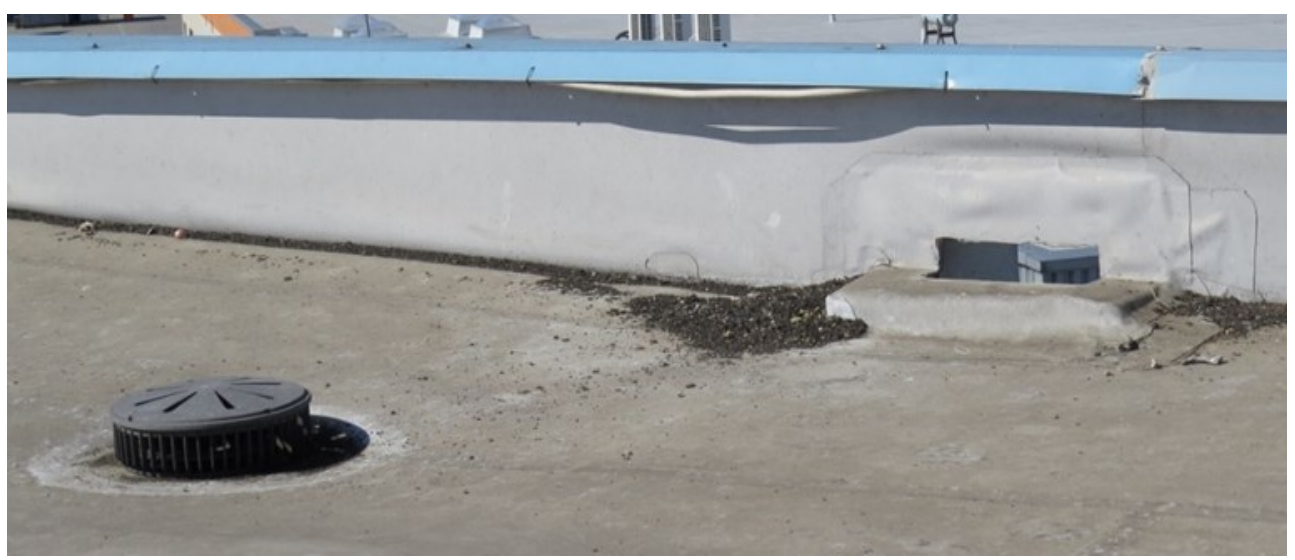

Fig. 7. Increase of the bottom edge of the emergency opening [4].

According to report by IMiGW [1], heavy rainfall, qualified as torrential rain, was accompanied by strong wind gusts that could reach $25 \mathrm{~m} / \mathrm{s}$ of speed, or higher still. This might "push" the rainwater already surging on the roof into certain points of the roof, causing additional overloads.

In case of a correctly performed vacuum installation, mounted in compliance with project of 2005, the capacity of the basic (drums) and emergency (safety overflows) systems should be sufficient to lead rainwater waste from the roof in case of torrential rain. During the renovation works performed in 2011 , both systems have been tampered with. The hydraulics of the inflow of rainwater waste into the drums was changed, thus practically preventing their emergency outflow.

The introduced changes were significant from a construction point of view, including both structural and sanitation aspects, and required implementation of new hydraulic calculations for the vacuum system along with the associated emergency overflows, which would justify the need for change. No such calculations were performed whatsoever.

\section{Summary}

Pursuant to the provisions of the Construction Law, renovation of existing buildings is based on restoring their original condition and does not require a building permit, except for objects included in the register of monuments - Art. 29 (2)(1), yet, it requires notification to the competent authority - Art. 30 (1)(2). The Contractor, as a participant in the construction process with building licenses, should be fully aware of this fact.

It would also have to be considered whether the changes made were eligible for renovation works, because they resulted in changes in structure of the roof, attica and rainwater installation. Therefore, instead of notification, one ought to apply for a building permit. Later, however, the term renovation was used for the fact that this term was used in the documentation submitted for an opinion.

The contractor's offer already included the following point: Profiling pitches along the troughs by means of fittings, while in annex 1 to the agreement, the scope of works includes profiling of pitches to roof drains by laying designed styrofoam wedges along the walls. No such project was found in the submitted documentation. The as-built documentation also lacks such a project.

In the semi-annual protocols on inspections made both before and after the roof renovation in 2011 , there were no differences in the description of the roofing. In all of the 
above-mentioned "roofing was made with Rephanol 1,2 PVC membrane from Bras", though in the as-built documentation it was replaced with Sikaplan 12 G PVC roof foil.

In the same semi-annual protocols one can find that the roof drainage system is carried out according to the Geberit Pluvia with 56 and $63 \mathrm{~mm}$ drain outlets. There is no information relating to the vacuum drainage system, being an integral part of safety overflows. There is no mention of this either in the description of the exterior walls or in the description of the roof. It seems that the changes in the direction of inclination of the roof made by inserting new styrofoam elements and the change to the structure and number of emergency overflows should be included in such a protocol, because such changes were of significant importance.

The analyzed protocols contain information on the roof load calculations, but they have not been submitted for analysis. One cannot therefore conclude what were the assumptions for locating the "rain gutters" before and after the renovation.

In the protocol from before the renovation in 2011 , there is a point which indicates, among others, the need to replace the roof drains with heated roof drains with height-adjustable mounting as well as reduce their height and replace the roofing. However, there is no indication of either a need to introduce changes in roof pitches or any interfere in the emergency overflows.

In the protocol performed after the roof renovation in 2011, the technical condition of the roof was assessed as good subject to the maintenance of local water stagnation resulting from construction errors during replacement of the roof membrane. In point: Conclusions and recommendations, there are no recommendations for repairing such a condition. It was recommended to perform periodic, or regular cleaning of the roof, which, however, does not remove the cause of water stagnation after rainfall. There is also no mention of the transfer of this stagnation towards the center span.

\section{Conclusions}

Changing the direction of the roof pitch by inserting elevating styrofoam elements and changing both the structure and number of emergency overflows resulted in accumulation of rainfall in a new, previously unforeseen trough. Such actions have led to an overload of the roof structure and collapse of its parts, and thus ultimately to the construction disaster.

The damages occurred in the north-west corner in the three $3 \times 18 \mathrm{~m}$ aisles at the width of two $2 \times 6 \mathrm{~m}$ space at an area of approx. $650 \mathrm{~m}^{2}$. The steel structure of the roof, including beams, purlins, bracings, internal and external support columns as well as outer walls, and part of electrical and hydrant installations, were all damaged. Roof damage also included the central portion of the hall's front elevation at an area of approx. $180 \mathrm{~m}^{2}$.

The disaster was also prompted by the reduction, made during the roof renovation in 2011 , of the number and size of safety overflows - by $75 \%$ in the warehouse area and by $45 \%$ in the office part, as well as increase of the overflow edge with respect to the lowest point of the roof plane by approx. $12-14 \mathrm{~cm}$. This was incompatible with the project from 2005 and contributed to the excessive accumulation of water on the roof, which thus exceeded the load capacity of the structure.

The downpour caused the accumulation of water at a distance of $3 \mathrm{~m}$ from the attic. The accumulated water was not discharged through the roof drains and emergency overflows, and lead to an exceed deflection of the roof structure, thus causing contraction of the outer wall to the center and fracture of the external, and hence consequently, the two internal columns. Permanent deflection of purlins, indicating the quantity of the accumulated water, reached approx. $1-1.5 \mathrm{~m}$. It was estimated that the water load was eight times higher than the structure's load capacity.

As viewed by the authors of the publication, the preliminary cause of the disaster determined by the Powiat Construction Supervision Inspector [2] - namely heavy rainfall and 
overload caused by the weight of the accumulated water - was one of the direct causes. It should be noted here that the owner has performed all the necessary additional expertise in relation to the construction works. Their results indicated neither flaws nor weakness in partitions before the disaster.

\section{References}

1. Report: Expert opinion by The Institute of Meteorology and Water Management (IMiGW) on the Approximate Atmospheric Conditions of $26^{\text {th }}$ June (2016)

2. The decision of the Powiat Construction Supervision Inspector

3. Documentation of the owner of the hall

4. Site inspection

5. Journal of Laws of 2010 No. 243 pos. 1623 - Construction Law Act of $7^{\text {th }}$ July (1994)

6. Journal of Laws of 2002 No. $\mathbf{7 5}$ pos. 690 - Ordinance of the Minister of Infrastructure of 12 April 2002 on the conditions to be met by buildings and their location (2002-2015)

7. PN-EN 12056-3:2002: Gravity drainage systems inside buildings - Part 3: Roof drainage, layout and calculation 